\title{
Memantine treatment for Japanese patients with moderate to severe Alzheimer's disease: a meta-analysis of double-blind, randomized, placebo-controlled trials
}

This article was published in the following Dove Press journal:

Neuropsychiatric Disease and Treatment

\author{
Taro Kishil,* \\ Shinji Matsunaga ${ }^{1,2, *}$ \\ Nakao Iwata' \\ 'Department of Psychiatry, Fujita \\ Health University School of Medicine, \\ Toyoake, Aichi 470- I 192, Japan; \\ ${ }^{2}$ Department of Geriatrics and \\ Cognitive Disorders, Fujita Health \\ University School of Medicine, \\ Toyoake, Aichi 470-I I 92, Japan \\ *These authors contributed equally \\ to this work
}

\begin{abstract}
Purpose: Although previous meta-analyses of randomized trials in the world literature have provided strong evidence that supports the efficacy and safety of memantine for the treatment of patients with Alzheimer's disease (AD), it is unclear whether the drug is beneficial in the treatment of Japanese patients with moderate to severe AD because of differences in the formulation and regimen of memantine and the cholinesterase inhibitor (ChEI) used in combination with memantine between the drugs made in Japan and those made in other countries. To address this issue, we conducted a meta-analysis on the efficacy and safety of memantine using data from only double-blind, randomized, placebo-controlled trials (DBRPCTs) in Japan on Japanese patients with moderate to severe AD.
\end{abstract}

Patients and methods: Our primary analysis was conducted using data from both memantine monotherapy (memantine vs placebo) and memantine combination therapy (memantine+ChEI vs ChEI+placebo) studies. The primary outcomes measured were cognitive function and behavioral disturbances. The secondary outcomes measured were the subscale scores of Behavioral Pathology in Alzheimer's Disease (Behave-AD), discontinuation rate, and individual adverse events.

Results: Four DBRPCTs $(n=1,328)$ were detected. Memantine was superior to the control in cognitive functions (standardized mean difference $[\mathrm{SMD}]=-0.31,95 \% \mathrm{CI}=-0.53,-0.10$ ) and behavioral disturbances $(\mathrm{SMD}=-0.16,95 \% \mathrm{CI}=-0.28,-0.05)$. Only memantine monotherapy was superior in both outcomes. It was also superior to the control in delusions, aggression, and diurnal rhythm disturbances based on the Behave-AD subscale scores. Although memantine was associated with a lower incidence of $\mathrm{AD}$ progression than that of the control, the incidence of somnolence was higher with memantine. There were no significant differences in other safety outcomes, including all-cause discontinuation, between the groups.

Conclusion: Our results suggest that memantine is useful for the treatment of patients in Japan with moderate to severe AD even though our meta-analysis comprised only four DBRPCTs.

Keywords: Japanese patients, Alzheimer's disease, memantine, cognitive functions, behavioral disturbances, meta-analysis

\section{Introduction}

Our previous meta-analysis demonstrated that memantine improves cognitive functions and behavioral disturbances in patients with Alzheimer's disease (AD) more efficiently than the controls, both as a monotherapy and in combination with donepezil. ${ }^{1}$ We demonstrated that memantine improves positive symptoms of behavioral 
disturbances, such as agitation/aggression, delusions, disinhibition, and nighttime disturbance/diurnal rhythm disturbances in patients with AD. ${ }^{2}$ The medication was also shown to be well tolerated based on no difference in all-cause discontinuation between those treated with memantine and the controls. ${ }^{1}$ Moreover, although the meta-analysis comprised more than 200 safety outcomes, there were no significant differences in these outcomes between the groups with respect to safety except for differences in somnolence and dizziness. ${ }^{1}$

However, even with our results, our question of whether memantine is beneficial in the treatment of Japanese patients with moderate to severe AD remained unanswered., ${ }^{1,2}$ Although our previous meta-analysis included all randomized controlled trials on memantine for patients with AD worldwide, there are differences in the formulation and regimen of the medication and of the cholinesterase inhibitor (ChEI) used in combination with memantine among countries. First, there are two formulations of memantine: immediate-release and extended-release. ${ }^{3-7}$ For example, the U.S. Food and Drug Administration (FDA) approves $28 \mathrm{mg} / \mathrm{d}$ extended-release memantine for the treatment of moderate to severe AD in the US; ${ }^{4}$ however, in Japan, only $20 \mathrm{mg} / \mathrm{d}$ immediate-release memantine was approved for treatment of the same condition. ${ }^{7}$ Other countries approve $10 \mathrm{mg}$ BID immediate-release memantine for the treatment of moderate to severe AD. ${ }^{5,6}$ Second, although we included data from studies on low-dose memantine ( $<20 \mathrm{mg} / \mathrm{d}$ ), $20 \mathrm{mg} / \mathrm{d}$ immediate-release memantine (or $28 \mathrm{mg} / \mathrm{d}$ extended-release memantine) was approved worldwide for the treatment of moderate to severe AD. Third, there is a difference in the approved dosage of donepezil among the countries. FDA approves 5 or $10 \mathrm{mg} / \mathrm{d}$ donepezil for mild to moderate AD, and 10 or $23 \mathrm{mg} / \mathrm{d}$ for moderate to severe AD. In Japan, $5 \mathrm{mg} / \mathrm{d}$ donepezil is approved for mild to moderate AD, and $10 \mathrm{mg} / \mathrm{d}$ donepezil is approved for severe AD. Recent metaanalyses have shown that there were significant differences in the efficacy and safety between high-dose donepezil and $5 \mathrm{mg}$ donepezil. ${ }^{8}$ Fourth, although there are three formulations of rivastigmine (capsules, liquid solution, and patches) worldwide, only the patches are approved for the treatment of AD in Japan. The current meta-analysis of rivastigmine showed that the transdermal patch might have fewer side effects than the capsules. ${ }^{9}$

For direct evidence to answer our clinical question, we performed a meta-analysis of the efficacy and safety of memantine immediate-release using data from only doubleblind, randomized, placebo-controlled trials (DBRPCTs) in Japan on Japanese patients with moderate to severe AD.
Although our previous meta-analysis included the treatment arms for both 10 and $20 \mathrm{mg} / \mathrm{d}$ memantine, ${ }^{1,2}$ the current metaanalysis used data from only the treatment arm with $20 \mathrm{mg} / \mathrm{d}$ memantine to determine efficacy in Japan. ${ }^{7}$ Our primary analysis was conducted using data from both memantine monotherapy and memantine combination therapy studies because there were only four DBRPCTs included in the current meta-analysis; however, we included data from both 10 and $20 \mathrm{mg} / \mathrm{d}$ memantine to conduct our current meta-analysis of specific safety characteristics. Given that only $5 \mathrm{mg} / \mathrm{d}$ memantine is first administered and the dose is increased by $5 \mathrm{mg} / \mathrm{d}$ weekly up to $20 \mathrm{mg} / \mathrm{d}$, ${ }^{7}$ we considered that the safety profile of lower dose memantine $(<20 \mathrm{mg} / \mathrm{d})$ must be evaluated.

\section{Materials and methods Search strategy and inclusion criteria}

To identify relevant studies, two study authors (TK and SM) independently searched MEDLINE, Cochrane Library, Scopus, and PsycINFO without language restrictions from the inception of these databases to September 5, 2018, using the following search strategy: ("Alzheimer Disease" [Mesh] OR "Alzheimer disease" OR "Alzheimer's disease") AND ("Memantine" [Mesh] OR "memantine") AND ("randomized" OR "random" OR "randomly") AND ("Japanese" OR "Japan"). The authors also searched ClinicalTrials.gov (http://clinicaltrials.gov/), UMIN (http://www.umin.ac.jp/), and the International Clinical Trials Registry Platform (http:// www.who.int/ictrp/en/) to include DBRPCTs as comprehensively as possible and to minimize the possibility of publication bias. Only DBRPCTs of memantine treatment lasting $>12$ weeks in Japanese patients with moderate to severe AD were included. Two study authors (TK and SM) independently assessed the inclusion/exclusion criteria and selected the studies. The references of the included articles and review articles were also searched for citations on additional relevant published and unpublished studies, including conference abstracts.

\section{Data synthesis and outcome measures}

Three primary outcomes were assessed based on two efficacy measures as follows: improvement in cognitive functions and behavioral disturbances. Cognitive function scores were derived from the Alzheimer's Disease Assessment Scale, cognitive subscale ${ }^{10}$ score (which IE2201 study ${ }^{11}$ used), and Severe Impairment Battery (SIB) ${ }^{12}$ score (which Kitamura 2011 study ${ }^{13}$ Nakamura 2011 study, ${ }^{14}$ and Nakamura 2016 study ${ }^{15}$ used). The behavioral disturbances score comprised 
the Neuropsychiatric Inventory ${ }^{16}$ score (which Kitamura 2011 study $^{13}$ used) and the Behavioral Pathology in Alzheimer's Disease Rating Scale ${ }^{17}$ score (which Nakamura 2011 study ${ }^{14}$ and Nakamura 2016 study ${ }^{15}$ used). The secondary outcome measures were the improvement of Behave-AD subscale scores, all-cause discontinuation, discontinuation because of adverse events, and the incidence of individual adverse events.

\section{Data extraction}

Two study authors (TK and SM) independently extracted data from the included studies. Where possible, we used only an intention-to-treat or a full analysis set (FAS) population. When the data required for a meta-analysis were missing, we contacted the investigators (or the industries) of the relevant study and requested unpublished data.

\section{Meta-analysis methods}

The meta-analysis was conducted using Review Manager software. ${ }^{18}$ The random-effects model was selected for this meta-analysis because of the potential heterogeneity across studies. Dichotomous outcomes were presented as risk ratios (RRs) with 95\% CIs. When the random-effects model showed significant differences among groups, the number needed to harm $(\mathrm{NNH})$ was calculated. $\mathrm{NNH}$ values were then derived from the risk difference (RD) using the formula $\mathrm{NNH}=1$ / $\mathrm{RD}$. Continuous outcomes were analyzed using the mean difference (MD) or, when different studies used different scales, the standardized mean difference (SMD). Lower SIB scores indicate more impairment or more severe symptoms; hence, we reversed the algebraic sign of the numerical scores for these scales. We assessed the quality of the trial methods according to the Cochrane risk-of-bias criteria. ${ }^{19}$ Most commonly discussed in the Cochrane Handbook for Systematic Reviews of Interventions is the SMD, also known as Cohen's $\mathrm{d},{ }^{19}$ which is the MD divided by the pooled standard deviation of the two groups. For the SMD, a negligible effect is considered to range from 0.0 to 0.2 , a small effect is between 0.2 and 0.5 , a medium effect ranges from 0.5 to 0.8 , and a large effect is considered to be $>0.8 .^{19}$

Study heterogeneity was tested using the $I^{2}$ statistic, considering $I^{2} \geq 50 \%$ to reflect considerable heterogeneity. ${ }^{19}$ In addition, we performed a sensitivity/subgroup analysis by dividing the primary analysis of the primary outcomes into memantine monotherapy and combination therapy studies. Because there was difference in percentage of males among the DBRPCTs included in the current meta-analysis (Table 1), a meta-regression analysis was performed to evaluate the association between meta-analysis results for cognitive functions or behavioral disturbances and percentage of males using Comprehensive Meta-Analysis software version 2 (Biostat Inc., Englewood, NJ, USA). Egger's regression test was used to detect publication bias in the meta-analyses using the same software.

\section{Results \\ Study characteristics}

Of the 35 results obtained from our literature search, 21 were excluded because they were duplicates, 11 after a review of the abstract or title, and two after a review of the full text (two review articles) ${ }^{1,2}$ In addition, three studies ${ }^{11,14,15}$ were retrieved by searching through the review articles. ${ }^{1,2} \mathrm{We}$ did not detect any new DBRPCTs from the clinical trial registries. Four DBRPCTs (memantine monotherapy vs placebo: two DBRPCTs, $n=747$; combination therapy with memantine and ChEIs vs ChEI monotherapy: two DBRPCTs, $\mathrm{n}=581$ ) were identified..$^{11,13-15}$ All DBRPCTs were published in Japanese and sponsored by a pharmaceutical company (Table 1). The study design for all DBRPCTs was the same (ie, 24 weeks, DBRPCTs) (Table 1). The researchers used a FAS population. Evaluations regarding the quality of the study methods that included DBRPCTs were conducted according to the Cochrane risk-of-bias criteria, as shown in our previous article. ${ }^{1}$

\section{Efficacy outcomes}

Memantine was shown to significantly improve two primary efficacy outcomes compared with the control - cognitive function $(\mathrm{SMD}=-0.31,95 \% \mathrm{CIs}=-0.53$ to $-0.10, P=0.004$, $\left.I^{2}=61 \% ; \mathrm{N}=4, \mathrm{n}=1,192\right)$ and behavioral disturbances $\left(\mathrm{SMD}=-0.16,95 \% \mathrm{CIs}=-0.28\right.$ to $-0.05, P=0.006, I^{2}=0 \%$; $\mathrm{N}=3, \mathrm{n}=1,166$ ) (Figure 1). The data on cognitive function and behavioral disturbances scores in each treatment group were simulated with no publication bias (Egger's test $P$-value: cognitive function scores $=0.463$, behavioral disturbances score $=0.509$ ).

The sensitivity/subgroup analyses showed that only memantine monotherapy was superior to the controls in both primary outcomes (cognitive function scores of memantine monotherapy: $\mathrm{SMD}=-0.41,95 \% \mathrm{CIs}=-0.57$ to -0.26 , $P<0.00001, I^{2}=0 \%$, behavioral disturbances score of memantine monotherapy: $\mathrm{SMD}=-0.21,95 \% \mathrm{CIs}=-0.37$ to -0.06 , $\left.P=0.007, I^{2}=0 \%\right)$. Meta-regression analysis detected no associations between the effect size of memantine treatments with respect to cognitive functions or behavioral disturbances and percentage of males. 


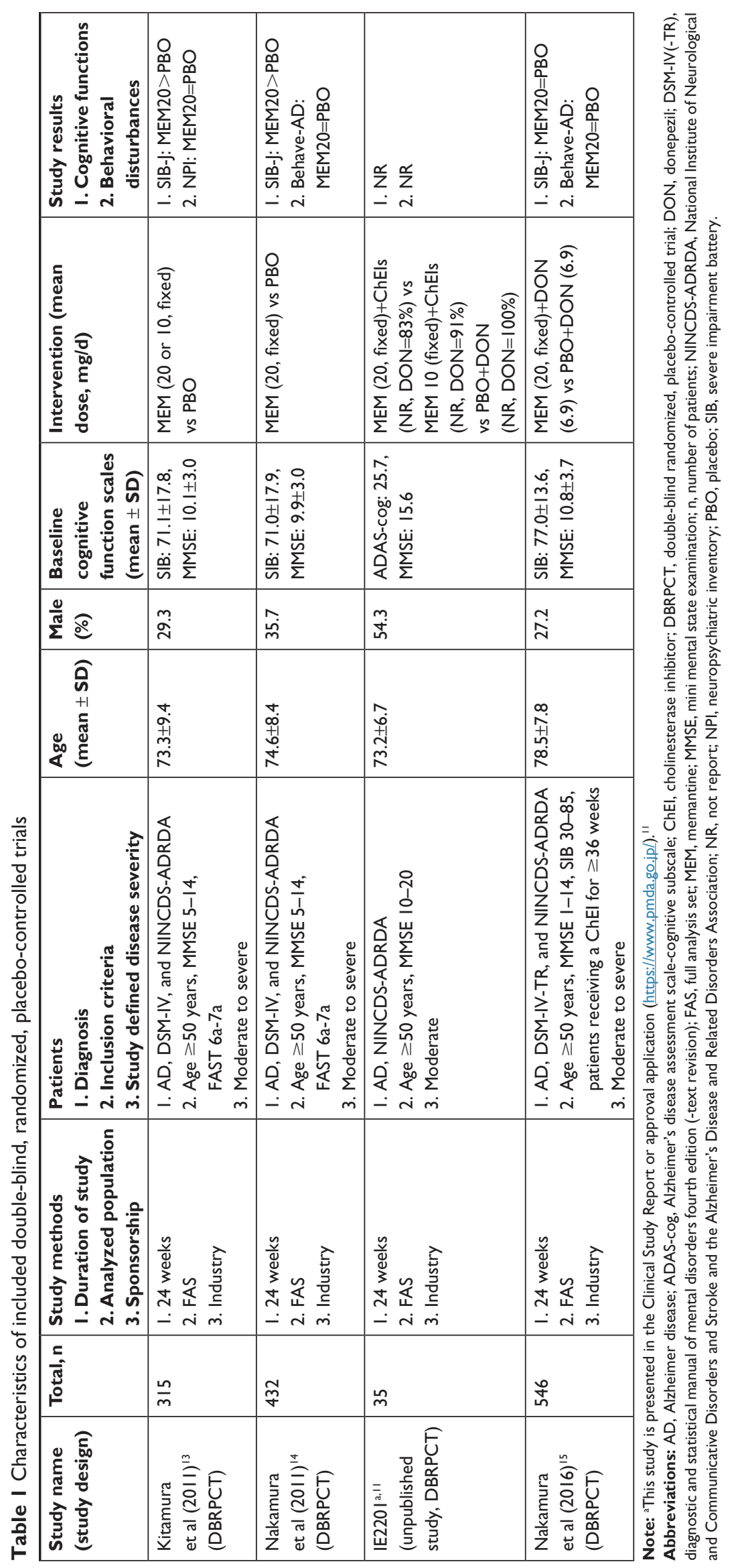




\begin{tabular}{|c|c|c|c|c|c|c|c|c|c|c|c|c|}
\hline $\begin{array}{l}\text { Study or } \\
\text { subgroup }\end{array}$ & $\begin{array}{l}\text { Meman } \\
\text { Mean }\end{array}$ & SDe & Total & $\begin{array}{l}\text { Contro } \\
\text { Mean }\end{array}$ & SD & Total & $\begin{array}{l}\text { Weight } \\
(\%)\end{array}$ & $\begin{array}{l}\text { Std mean difference } \\
\text { IV, random, } 95 \% \mathrm{Cl}\end{array}$ & \multicolumn{4}{|c|}{$\begin{array}{l}\text { Std mean difference } \\
\mathrm{IV} \text {, random, } 95 \% \mathrm{CI}\end{array}$} \\
\hline \multicolumn{13}{|l|}{ Cognitive functions } \\
\hline IE2201 & -0.6 & 4.81 & 12 & 3.16 & 6.9 & 12 & 5.8 & $-0.61(-1.43,0.21)$ & & & & \\
\hline Kitamura 2011 & -0.1 & 6.54 & 100 & 3.42 & 9.84 & 107 & 25.7 & $-0.42(-0.69,-0.14)$ & & $\longrightarrow$ & & \\
\hline Nakamura 2011 & 0.42 & 9.87 & 218 & 4.87 & 11.66 & 206 & 33.1 & $-0.41(-0.60,-0.22)$ & & - 블- & & \\
\hline Nakamura 2016 & 1.34 & 8.267 & 268 & 2.15 & 8.151 & 269 & 35.3 & $-0.10(-0.27,0.07)$ & & & & \\
\hline Subtotal $(95 \% \mathrm{Cl})$ & & & 598 & & & 594 & 100 & $-0.31(-0.53,-0.10)$ & & & & \\
\hline \multicolumn{13}{|c|}{$\begin{array}{l}\text { Heterogeneity: } \tau^{2}=0.03 ; \chi^{2}=7.79, d f=3(P=0.05) ; I^{2}=61 \% \\
\text { Test for overall effect: } Z=2.91(P=0.004)\end{array}$} \\
\hline \multicolumn{13}{|c|}{ Behavioral disturbances } \\
\hline Kitamura 2011 & -1.73 & 8.9 & 100 & -0.38 & 9.92 & 107 & 17.8 & $-0.14(-0.42,0.13)$ & & & & \\
\hline Nakamura 2011 & -0.25 & 4.22 & 217 & 0.91 & 5.08 & 208 & 36.3 & $-0.25(-0.44,-0.06)$ & & $\rightarrow-$ & & \\
\hline Nakamura 2016 & -0.1 & 3.7 & 267 & 0.3 & 4.1 & 267 & 45.9 & $-0.10(-0.27,0.07)$ & & & & \\
\hline Subtotal $(95 \% \mathrm{Cl})$ & & & 584 & & & 582 & 100 & $-0.16(-0.28,-0.05)$ & & & & \\
\hline \multirow{2}{*}{\multicolumn{13}{|c|}{$\begin{array}{l}\text { Heterogeneity: } \tau^{2}=0.00 ; \chi^{2}=1.28, d f=2(P=0.53) ; I^{2}=0 \% \\
\text { Test for overall effect: } Z=2.77(P=0.006)\end{array}$}} \\
\hline & & & & & & & & & & & & \\
\hline & & & & & & & & & -1 & -0.5 & 0.5 & 1 \\
\hline & & & & & & & & & \multicolumn{2}{|c|}{ Favors memantine } & Favor & ontrol \\
\hline
\end{tabular}

Figure I Cognitive function and behavioral disturbances.

Memantine was also superior to the control in delusions, aggression, and diurnal rhythm disturbances based on Behave-AD subscale scores (Figure 2).

\section{Safety outcomes}

Although memantine was associated with a lower incidence of the progression of $\mathrm{AD}$ than the control, the drug was associated with a higher incidence of somnolence than the control (Table 2). There were no significant differences in other safety outcomes, including all-cause discontinuation, between the groups (Table 2).

\section{Discussion}

The current meta-analysis was conducted using data from only Japanese patients with moderate to severe AD based on DBRPCTs in Japan. Memantine was superior to the control in improving cognitive function and behavioral disturbances. The results of the current meta-analysis were similar to those of previous meta-analyses, including all randomized trials of memantine for the treatment of $\mathrm{AD}$ worldwide; however, although our previous meta-analysis exhibited that both monotherapy and combination therapy with donepezil were superior to treatment with placebo in improving cognitive function and behavioral disturbances scores, ${ }^{1}$ the current meta-analysis showed that only memantine monotherapy was superior to the controls in those outcomes. We considered several reasons for these results. First, although there were two DBRPCTs using combination therapy, one of the two was a very small study $(n=35)$. There was also only one DBRPCT using combination therapy in the behavioral disturbances score; therefore, we might not be able to detect the superiority of memantine over the control in these efficacy outcomes because of insufficient statistical power. Second, the safety profile of ChEI (most of the patients included in the current meta-analysis received donepezil, Table 1) might be a confounding factor in the results of subgroup meta-analysis of combination therapy because a recent systematic review and meta-analysis of donepezil reported that the drug was associated with a higher incidence of anorexia $(10 \mathrm{mg} / \mathrm{d})$, diarrhea (5 and $10 \mathrm{mg} / \mathrm{d})$, dizziness $(10 \mathrm{mg} / \mathrm{d})$, fatigue $(10 \mathrm{mg} / \mathrm{d})$, hallucinations $(10 \mathrm{mg} / \mathrm{d})$, insomnia $(10 \mathrm{mg} / \mathrm{d})$, muscle cramps (5 and $10 \mathrm{mg} / \mathrm{d})$, nausea $(10 \mathrm{mg} / \mathrm{d})$, peripheral edema $(10 \mathrm{mg} / \mathrm{d})$, tremor $(10 \mathrm{mg} / \mathrm{d})$, vertigo $(10 \mathrm{mg} / \mathrm{d})$, vomiting $(10 \mathrm{mg} / \mathrm{d})$, and weight loss $(10 \mathrm{mg} / \mathrm{d})$ than those observed with placebo treatment. Further studies are necessary to investigate whether combination therapy is beneficial in the treatment of $\mathrm{AD}$ in Japanese patients.

Although memantine also improved positive symptoms of behavioral disturbances (delusions, aggression, and diurnal rhythm disturbances), it did not increase any negative symptoms such as mood. These results were similar to those of the previous meta-analysis. ${ }^{2}$ Moreover, memantine was associated with a lower incidence of the progression of AD compared with the control. Although memantine was associated with a higher incidence of somnolence than the control, there were no significant differences in other safety outcomes, including all-cause discontinuation, between the groups. We considered that memantine was well tolerated by Japanese patients with moderate to severe AD. 


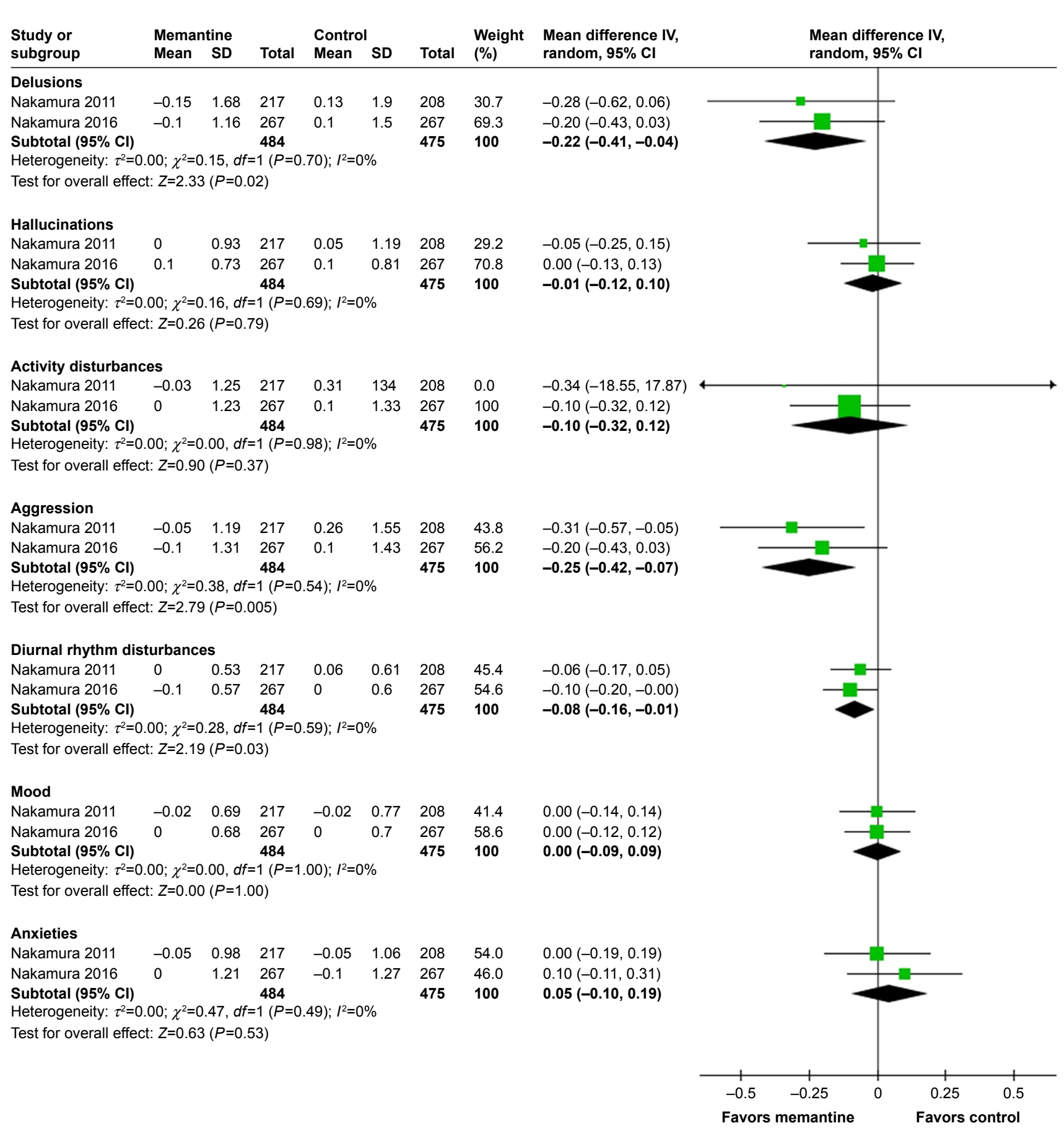

Figure 2 Behavioral pathology in Alzheimer's Disease Rating Scale subscale.

Table 2 Safety outcomes

\begin{tabular}{|l|l|l|l|l|l|}
\hline & $\mathbf{N}$ & $\mathbf{n}$ & $\mathbf{I}^{\mathbf{2}}$ & $\mathbf{R R}(\mathbf{9 5 \%}$ Cls) & P-value \\
\hline All-causes discontinuation & 4 & $\mathrm{I}, 328$ & $3 \mathrm{I} \%$ & $0.98(0.7 \mathrm{I}, \mathrm{I} .37)$ & 0.93 \\
\hline Discontinuation due to adverse events & 4 & $\mathrm{I}, 328$ & $45 \%$ & $0.88(0.5 \mathrm{I}, \mathrm{I} .53)$ & 0.66 \\
\hline Discontinuation due to death & 4 & $\mathrm{I}, 328$ & $0 \%$ & $\mathrm{I} .70(0.5 \mathrm{I}, 5.72)$ & 0.39 \\
\hline Abdominal pain & 2 & 747 & $0 \%$ & $\mathrm{I} .07(0.21,5.36)$ & 0.93 \\
\hline Abnormal behavior & 4 & $\mathrm{I}, 328$ & $0 \%$ & $0.66(0.22,1.96)$ & 0.45 \\
\hline Abnormal gait & 3 & 782 & $0 \%$ & $0.90(0.29,2.82)$ & 0.86 \\
\hline
\end{tabular}

(Continued) 
Table 2 (Continued)

\begin{tabular}{|c|c|c|c|c|c|}
\hline & $\mathbf{N}$ & $\mathbf{n}$ & $I^{2}$ & RR (95\% Cls) & $P$-value \\
\hline Aggression & 2 & 747 & $0 \%$ & $0.90(0.17,4.62)$ & 0.90 \\
\hline Agitation & 2 & 747 & $0 \%$ & $1.06(0.30,3.72)$ & 0.93 \\
\hline AD & 3 & 782 & $0 \%$ & $0.45(0.22,0.91)$ & $0.03(\mathrm{NNH}=33)$ \\
\hline Anorexia/appetite decreased & 3 & 1,293 & $0 \%$ & I.40 $(0.68,2.85)$ & 0.36 \\
\hline Anxiety & 2 & 747 & $0 \%$ & $0.56(0.23,1.36)$ & 0.20 \\
\hline Aphasia & 2 & 747 & $0 \%$ & $2.12(0.22,20.30)$ & 0.51 \\
\hline At least one adverse event & 4 & 1,328 & $0 \%$ & $1.04(0.98,1.11)$ & 0.22 \\
\hline At least one serious adverse event & 3 & 1,293 & $0 \%$ & $0.92(0.65,1.30)$ & 0.63 \\
\hline Back pain & 4 & 1,328 & $18 \%$ & $0.92(0.43,1.99)$ & 0.84 \\
\hline Cardiac failure & 3 & $\mathrm{I}, 293$ & $0 \%$ & $1.57(0.27,9.03)$ & 0.61 \\
\hline Cataract & 3 & 782 & $0 \%$ & $0.80(0.28,2.31)$ & 0.68 \\
\hline Constipation & 3 & 1,293 & $0 \%$ & $1.20(0.83,1.73)$ & 0.33 \\
\hline Dehydration & 3 & 1,293 & $0 \%$ & $1.23(0.4 \mathrm{I}, 3.70)$ & 0.71 \\
\hline Delirium & 2 & 747 & $0 \%$ & $2.04(0.27,15.13)$ & 0.49 \\
\hline Delusion/hallucination & 3 & 782 & $0 \%$ & $\mathrm{I} .17(0.3 \mathrm{I}, 4.3 \mathrm{I})$ & 0.82 \\
\hline Diabetes & 3 & 782 & $0 \%$ & $3.84(0.68,21.63)$ & 0.13 \\
\hline Diarrhea & 4 & 1,328 & $0 \%$ & $0.78(0.46,1.32)$ & 0.35 \\
\hline Dizziness/vertigo & 4 & $\mathrm{I}, 328$ & $0 \%$ & $1.84(0.92,3.66)$ & 0.08 \\
\hline Edema & 3 & 782 & $6 \%$ & $0.71(0.33,1.52)$ & 0.38 \\
\hline Fall & 4 & 1,328 & $0 \%$ & $0.88(0.59,1.31)$ & 0.53 \\
\hline Fatigue & 2 & 747 & $0 \%$ & $0.7 \mathrm{I}(0.07,6.77)$ & 0.76 \\
\hline Fever & 3 & 782 & $0 \%$ & $\mathrm{I} .08(0.5 \mathrm{I}, 2.27)$ & 0.84 \\
\hline Headache & 2 & 747 & $0 \%$ & $1.07(0.40,2.84)$ & 0.89 \\
\hline Insomnia & 3 & 1,293 & $0 \%$ & $\mathrm{I} .29(0.76,2.2 \mathrm{I})$ & 0.35 \\
\hline Irritability & 2 & 747 & $0 \%$ & $3.54(0.42,30.11)$ & 0.25 \\
\hline Muscle weakness & 2 & 747 & $0 \%$ & I.I8 $(0.15,9.56)$ & 0.88 \\
\hline Nasopharyngitis & 4 & 1,328 & $17 \%$ & $0.94(0.69,1.29)$ & 0.72 \\
\hline Nausea & 3 & 782 & $26 \%$ & $0.84(0.15,4.77)$ & 0.84 \\
\hline Parkinsonism & 2 & 467 & $0 \%$ & $2.83(0.32,24.99)$ & 0.35 \\
\hline Rash & 2 & 747 & $34 \%$ & $1.16(0.14,9.74)$ & 0.89 \\
\hline Renal failure & 2 & 747 & $0 \%$ & $1.18(0.15,9.56)$ & 0.88 \\
\hline Seizure & 3 & 1,293 & $0 \%$ & $1.14(0.22,5.91)$ & 0.87 \\
\hline Somnolence & 3 & 1,293 & $0 \%$ & $2.87(1.09,7.55)$ & 0.03 (NNH=ns) \\
\hline Vomiting & 3 & 782 & $7 \%$ & $0.62(0.27,1.43)$ & 0.26 \\
\hline Weight decreased & 2 & 747 & $0 \%$ & $1.08(0.49,2.39)$ & 0.85 \\
\hline Weight increased & 2 & 747 & $0 \%$ & I.78 $(0.46,6.86)$ & 0.40 \\
\hline
\end{tabular}

Notes: Bold face: memantine was associated with a lower incidence of the outcome than the control. Italic face: memantine was associated with a higher incidence of the outcome than the control.

Abbreviations: $\mathrm{AD}$, Alzheimer's disease; $\mathrm{N}$, number of studies; $\mathrm{n}$, number of patients; $\mathrm{NNH}$, number needed to harm; ns, not significant; RR, risk ratio.

\section{Conclusion}

We concluded that memantine was highly useful as a treatment for Japanese patients with moderate to severe AD. Although this current meta-analysis did not compare memantine with other antidementia drugs in Japanese patients with $\mathrm{AD}$, a network meta-analysis that includes all antidementia drugs and that uses data from only Japanese patients with $\mathrm{AD}$ will be necessary to evaluate their safety and efficacy.

\section{Acknowledgment}

Part of the data which we could not obtain from published articles or unpublished studies was provided by Daiichi Sankyo Co., Ltd.

\section{Disclosure}

Drs Kishi, Matsunaga, and Iwata declare that they have no direct conflicts of interest relevant to this study. No grant 
support or other sources of funding were used to conduct this study or prepare this manuscript. Dr Kishi has received speaker's honoraria from Daiichi Sankyo, Dainippon Sumitomo, Eisai, Janssen, Otsuka, Meiji, MSD, Yoshitomi, and Tanabe-Mitsubishi and has received a Health Labour Sciences Research Grant and a Fujita Health University School of Medicine research grant for other studies. Dr Matsunaga has received speaker's honoraria from Daiichi Sankyo, Dainippon Sumitomo, Eisai, Janssen, Meiji, MSD, Novartis, Otsuka, and Tanabe-Mitsubishi and has received a Fujita Health University School of Medicine research grant and a grant-in-aid for Young Scientists (B) for other studies. Dr Iwata has received speaker's honoraria from Astellas, Dainippon Sumitomo, Eli Lilly, GlaxoSmithKline, Janssen, Yoshitomi, Otsuka, Meiji, Shionogi, Novartis, and Pfizer and has received research grants from GlaxoSmithKline, Meiji, and Otsuka for other studies.

\section{References}

1. Kishi T, Matsunaga S, Oya K, Nomura I, Ikuta T, Iwata N. Memantine for Alzheimer's disease: an updated systematic review and meta-analysis. J Alzheimers Dis. 2017;60(2):401-425.

2. Kishi T, Matsunaga S, Iwata N. The effects of memantine on behavioral disturbances in patients with Alzheimer's disease: a meta-analysis. Neuropsychiatr Dis Treat. 2017;13:1909-1928.

3. Namenda I.R. Namenda IR (USA) drug package insert. Available from: https://www.accessdata.fda.gov/drugsatfda_docs/label/2013/021487s01 0s012s014,021627s0081bl.pdf

4. Namenda X.R. Namenda XR (USA) drug package insert. Available from: https://www.accessdata.fda.gov/drugsatfda_docs/label/ 2010/022525s0001bl.pdf

5. Axura. Axura drug package insert. Available from: https://www. ema.europa.eu/documents/product-information/axura-epar-productinformation_en.pdf. Accessed September 5, 2018.

6. Ebixa. Ebixa drug package insert. Available from: https://www. ema.europa.eu/documents/product-information/ebixa-epar-productinformation_en.pdf. Accessed September 5, 2018.
7. Memary. Memary (Japan) drug package insert. Available from: http:// www.info.pmda.go.jp/downfiles/ph/PDF/430574_1190018F1023_1_ 17.pdf

8. Birks JS, Harvey RJ. Donepezil for dementia due to Alzheimer's disease. Cochrane Database Syst Rev. 2018;6:CD001190.

9. Birks JS, Grimley Evans J. Rivastigmine for Alzheimer's disease. Cochrane Database Syst Rev. 2015;4:CD001191.

10. Rosen WG, Mohs RC, Davis KL. A new rating scale for Alzheimer's disease. Am J Psychiatry. 1984;141(11):1356-1364.

11. Pharmaceuticals and Medical Devices Agency: Available from: http:// www.pmda.go.jp/drugs/2011/P201100018/43057400_22300AMX004 23_K101_2.pdf. Accessed September 5, 2018.

12. Panisset M, Roudier M, Saxton J, Boller F. Severe impairment battery. A neuropsychological test for severely demented patients. Arch Neurol. 1994;51(1):41-45.

13. Kitamura S, Homma A, Nakamura Y, Yoshimura I. Phase II study of memantine hydrochloride, a new NMDA receptor antagonist, in patients with moderate to severe Alzheimer's disease - Efficacy, safety and recommended dose. Japanese Journal of Geriatric Psychiatry. 2011;22(4): 453-463.

14. Nakamura Y, Homma A, Kitamura S, Yoshimura I. Phase III study of memantine hydrochloride, a new NMDA receptor antagonist, in patients with moderate to severe Alzheimer's disease - Efficacy and safety. Japanese Journal of Geriatric Psychiatry. 2011;22(4):464-473.

15. Nakamura Y, Kitamura S, Nagakubo T, Kobayashi M, Homma A. Study of Memantine Hydrochloride in Combination with Donepezil Hydrochloride in Patients with Moderate to Severe Alzheimer's disease Efficacy and safety. Japanese Journal of Geriatric Medicine. 2016; 54(11):1147-1158.

16. Cummings JL, Mega M, Gray K, Rosenberg-Thompson S, Carusi DA, Gornbein J. The Neuropsychiatric Inventory: comprehensive assessment of psychopathology in dementia. Neurology. 1994;44(12): 2308-2314.

17. Auer SR, Monteiro IM, Reisberg B. The empirical behavioral pathology in Alzheimer's disease (E-BEHAVE-AD) rating scale. Int Psychogeriatr. 1996;8(2):247-266.

18. The Cochrane Collaboration. Review Manager (RevMan) [Computer program]. Version 5.3. Copenhagen: The Nordic Cochrane Centre; 2014.

19. Higgins JPT, Green S. Cochrane Handbook for Systematic Reviews of Interventions. Version 5.1.0 [updated March 2011]. The Cochrane Collaboration; 2011. Available from: http://handbook.cochrane.org.
Neuropsychiatric Disease and Treatment

\section{Publish your work in this journal}

Neuropsychiatric Disease and Treatment is an international, peerreviewed journal of clinical therapeutics and pharmacology focusing on concise rapid reporting of clinical or pre-clinical studies on a range of neuropsychiatric and neurological disorders. This journal is indexed on PubMed Central, the 'PsycINFO' database and CAS,

\section{Dovepress}

and is the official journal of The International Neuropsychiatric Association (INA). The manuscript management system is completely online and includes a very quick and fair peer-review system, which is all easy to use. Visit http://www.dovepress.com/testimonials.php to read real quotes from published authors. 